\title{
Simulating Fuel Spill Fires Under the Wing of an Aircraft
}

\author{
N. R. KELTNER, W. GILL and L. A. KENT \\ Thermal Test Team - Energetic and Environmental Testing Department \\ Sandia National Laboratories, Albuquerque, NM, 87185-1135
}

\begin{abstract}
As part of a probablistic risk assessment program, estimates of the thermal exposure in aircraft crash fires were needed. Tests were conducted to simulate fuel spill fires that might occur under the wing of a C-141 transport aircraft. Measurements were made of the fire temperatures and the heat fluxes to the underside of the wing and the underwing fuselage surfaces. Both temperatures and heat fluxes are needed to adequately specify the fire exposure.
\end{abstract}

Direct comparisons between the average centerline temperatures measured at a given elevation in different sizes of fires showed poor agreement A scaling analysis using the total heat release rate gave promising results. Statistical analyses of the temperature and heat flux data were used to develop temperature-to-heat flux mappings. The heat fluxes from the current test series are significantly lower than prior data from large open pool fires.

\section{INTRODUCTION}

As part of a probablistic risk assessment (PRA) program sponsored by the Defense Nuclear Agency, models were needed to estimate the thermal exposure in aircraft crash fires in a large number of different accident scenarios. Predicting the relationship between fire temperatures and the heat flux incident on an object engulfed in a fire is a complex problem. Advanced fire physics model require state-of-the-art submodels (combustion, convection, multidimensional participating radiation, etc.) which are coupled with the flowfield governing momentum solution. Large computer times are required to run advanced models. Simplified models, such as the Gray Gas Model [1], apply first principles only to the dominating physical phenomena and rely on empirical factors to represent the remaining physics. These models, which are partially empirical, are being developed into predictive tools to reduce computer run times.

While these computer models are being developed and validated, an analysis of the existing data has been used to develop simplified temperature-to-heat flux mappings which reflect the general trends of the thermal exposure in open pool fires for vertical plates and horizontal cylinders. Data on fire temperature and the heat flux absorbed by different objects have been obtained in large pool fires at Sandia National Laboratories [2] in an attempt to understand 
the physical behavior of fires and to quantify the thermal response of radioactive material (RAM) shipping containers when subjected to transportation accident fire environments. Analyses of these data have demonstrated the importance of the coupling between the object and the fire on the observed heat flux levels [1]. The coupling depends on both the design of the object and the configuration of the test. Overall, this work has shown that both the temperature and the heat flux are needed to describe the thermal exposure of an object in a fire.

To account for differences in configuration between the earlier open pool tests and aircraft fires, a series of tests was conducted to simulate fires that might occur under the wing of a $\mathrm{C}$ 141 transport aircraft as a result of a fuel spill. The objectives were to:

1) Develop fire temperature * versus surface heat flux * data for an underwing area that includes the horizontal wing surface and the vertical fuselage surface.

2) Use these data to develop fire temperature versus heat flux ( $\mathrm{T}$ vs $\mathrm{q}$ ) mappings.

3) Compare this $T$ vs $q$ mapping to the mapping developed from earlier open pool fire tests.

4) Compare the fire temperature data with temperatures from other experiments.

\section{EXPERIMENTS}

\section{Test Setup}

The tests used the Inverted Deluge System (IDS) test fixture at Sandia's Lurance Canyon Burn Site. The IDS simulator [3] consists of a $7.3 \mathrm{~m} \mathrm{x} 12.2 \mathrm{~m}$ concrete pad to simulate an aircraft dock floor and a similarly sized sheet metal structure to simulate an aircraft wing (Figure 1). The IDS simulator was built to evaluate in-floor fire suppression systems for application in aircraft hangars. For the current tests, the fire suppression system was disabled and the fixture was modified to include a pool area on the floor and a simulated fuselage.

The IDS wing simulator was raised to its maximum height of $3.8 \mathrm{~m}$ above the pool floor; this is slightly less than the nominal underwing elevation on a C-141 aircraft. The fuselage was simulated by a $7.3 \mathrm{~m} \mathrm{x} 3.8 \mathrm{~m}$ steel plate mounted vertically at the east end of the pool. A steel shelf $(0.6 \mathrm{~m}$ wide) was used to simulate the effect of the landing gear pod (see Figure 1).

A $3.7 \mathrm{~m} \mathrm{x} 7.6 \mathrm{~m}$ pool, designed in two sections to allow fires of two sizes and three configurations, was placed at the east end of the fixture. The different sizes and configurations were used to evaluate the effect of fuel spill size and location on heat ransfer to the underwing and fuselage surfaces. Each half of the pool was equipped with a separate metered fuel line; this allowed filling of either or both sides with known amounts of fuel. Wind screens were placed

\footnotetext{
* Fire temperature is the temperature measured by either Inconel sheathed or bare wire thermocouples. The data from these thermocouples are not corrected for any measurement errors.

** Surface heat flux is the heat flux absorbed by the metal plate calorimeters plus a correction for radiation heat loss to the environment. This is often called a cold wall heat flux.
} 
around the testing area to reduce the effect of the wind on the fires; the screens are approximately $6 \mathrm{~m}$ high and placed in a nominal $15 \mathrm{~m}$ radius circle.

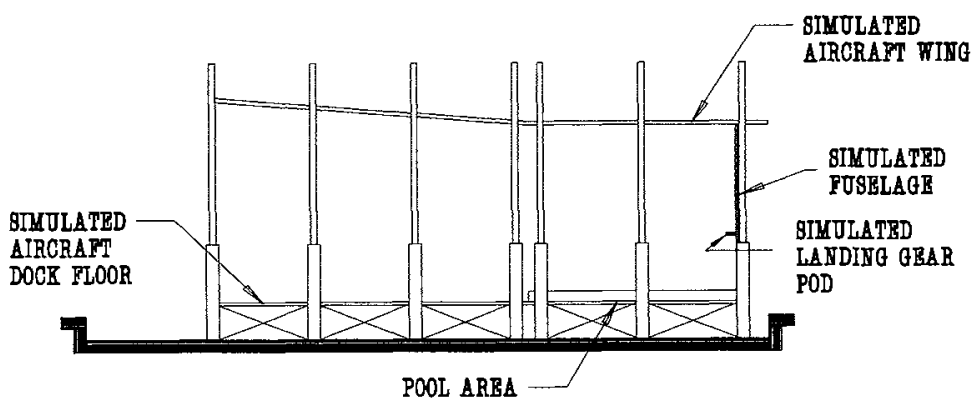

Figure 1 Side View of the Modified Inverted Deluge System

\section{Instrumentation}

A total of 24 measurement stations were installed on the aircraft wing simulator. These locations are shown as the numbered, square symbols in Figure 2. Each station consisted of a $300 \mathrm{~mm}$ square, $1.52 \mathrm{~mm}$ thick (16-gauge, $0.06 \mathrm{in}$ ), type 304 stainless steel plate held in place over cutouts in the sheet metal surface. The face of each stainless steel plate was painted with Pyromark Black to help ensure a known emissivity. Two temperature measurements were taken at each station. A thermocouple mounted on the unexposed surface of the plate was used to measure the plate temperature; a thermocouple extending $\sim 102 \mathrm{~mm}$ below the plate was used to measure the fire temperature. A typical station is shown in Figure 3.

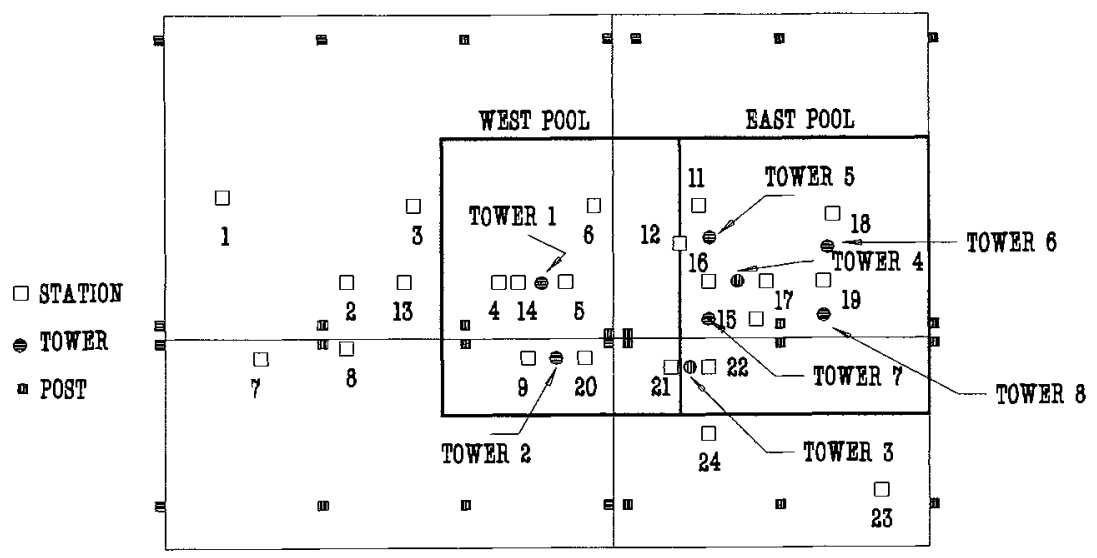

Figure 2 Instrumentation Layout on the Simulated Wing 


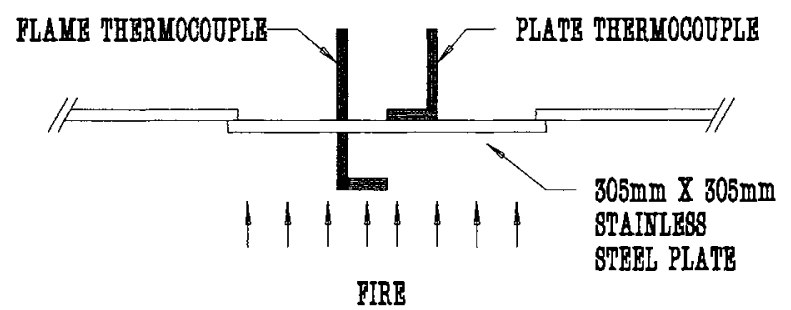

Figure 3 Instrumentation on the Measurement Stations

The fuselage simulator was instrumented in a similar manner. In this case, the back-face thermocouple was mounted directly on the sheet metal structure instead of on a stainless steel plate. There were six measurement locations as shown in Figure 4. The measurement locations on the aircraft wing simulator are referred to as "stations"; the measurement locations on the fuselage simulator are referred to as "plates".

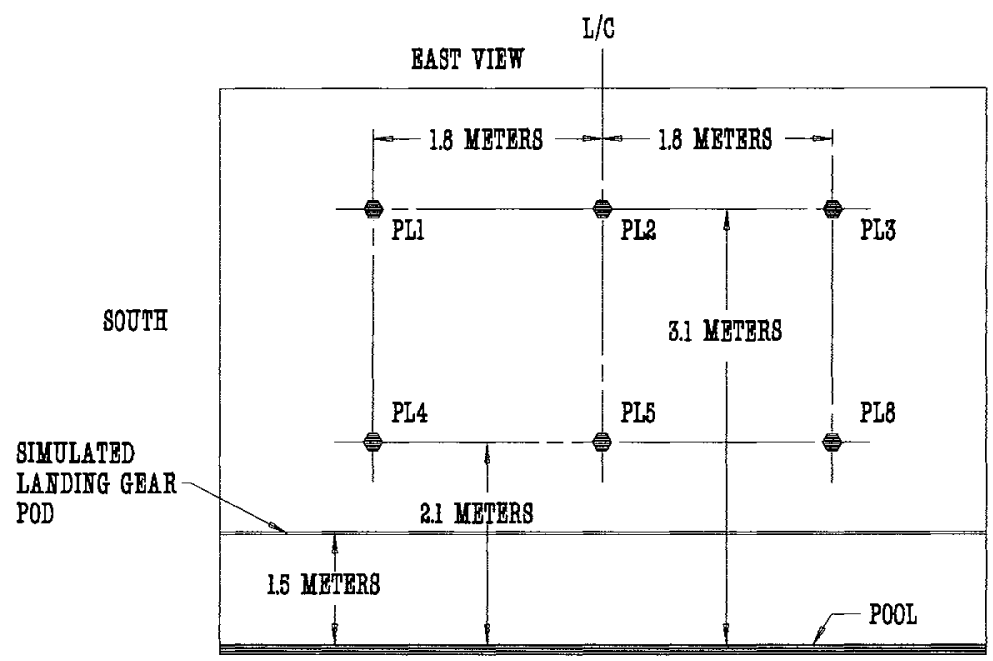

Figure 4 Instrumentation Layout on the Simulated Fuselage

A total of eight instrumentation towers were used for mounting fire temperature thermocouples at various locations. The locations of the towers are shown as circles in Figure 2. On each tower, thermocouples were placed at elevations of $1.2,2.1$, and 3.0 meters above the pool floor. 
Metal sheathed thermocouples (1.6 mm outside diameter, Inconel sheathed, type $\mathrm{K}$, ungrounded junction) were used to measure fire temperatures. To allow comparison of fire temperatures measured with sheathed thermocouples and bare wire thermocouples, bare wire thermocouples were mounted beside the sheathed fire thermocouples on towers 4,6 and 8 at elevations of 2.1 and 3.0 meters, at stations 18 and 19 , and at plates 2 and 5 .

\section{Test Procedure}

Prior to conducting a test, the pools were filled with $51 \mathrm{~mm}$ of water to provide a level surface and to protect the concrete floor. JP-4 fuel was floated on the water in either or both pools depending on the test configuration. For the half pool configuration, $\sim 95$ liters of JP-4 fuel was added to either the East or West pool to provide a fuel depth of $6.3 \mathrm{~mm}$ and a burn time of approximately 1 minute. When the Full pool configuration was used, 95 liters were added to each half of the pool.

When a rotating cup anemometer located inside the wind screens indicated nearly zero wind speed (by stopping), the data acquisition system was initiated. Several seconds later, a single point ignition system was used to start the fire. Figure 5 shows a typical temperature history from a tower.

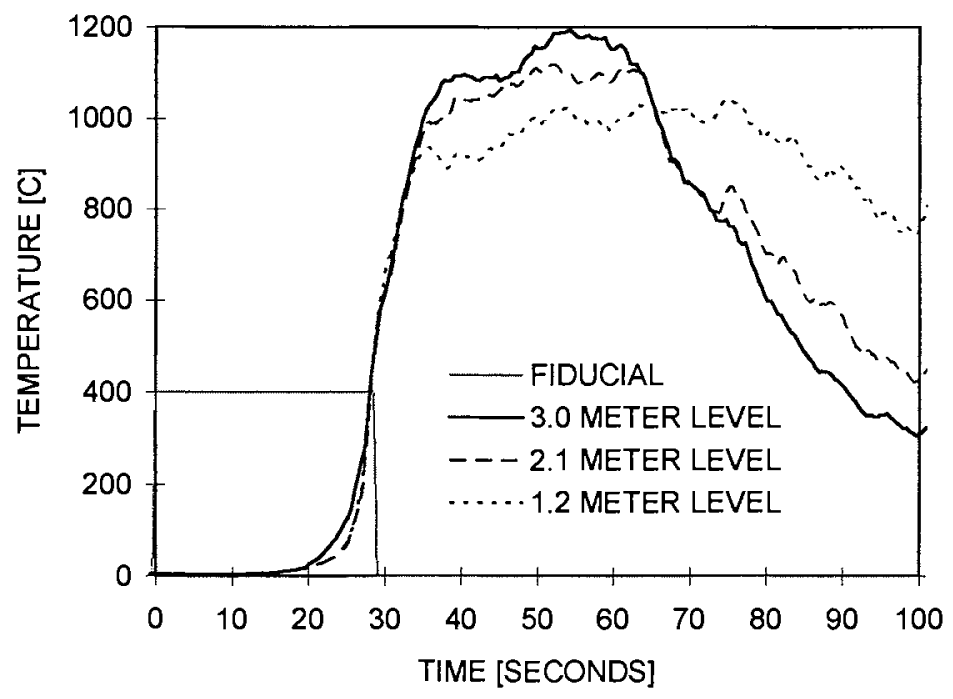

Figure 5 Temperature Histories on a Tower

Ten tests were conducted. The first test was a system checkout. There were three tests run with each pool configuration (East, West, and Full) to study the effects of pool size and location relative to the fuselage. 


\section{FIRE TEMPERATURES AND SURFACE HEAT FLUXES}

\section{Measurements}

Metal sheathed thermocouples and bare wire thermocouples represent the extremes used to measure temperatures in large fires. To address the objective of understanding the potential differences between the fire temperature measurements made by different laboratories, three towers, two stations, and two plates were equipped with pairs of fire thermocouples mounted at the same location as described above.

From a direct comparison of the measurements, the sheathed thermocouple measurements demonstrate a slower response and typically indicate slightly higher average temperatures with smaller standard deviations than the bare thermocouple measurements. From the 60 pairs of measurements during the tests, the average readings were within $\pm 10^{\circ} \mathrm{C}$ in 32 pairs. In 7 pairs, the bare thermocouple reads more than $10^{\circ} \mathrm{C}$ higher. In 21 pairs, the sheathed thermocouple reads more than $10^{\circ} \mathrm{C}$ higher. For the sheathed thermocouples, the higher averages may be attributable to reduced convective heat transfer on the larger diameter sheathed thermocouples. The standard deviations for the sheathed thermocouples are lower because the sheathed thermocouples have a larger time constant; as a result, the thermocouple acts somewhat like a filter [4]. Overall, these results indicate that thermocouple design differences are not a critical factor in measuring the average fire temperature. The differences may be important when determining the variance of the temperature.

To calculate surface heat fluxes, an empirically determined differential ( first order, low pass system; time constant $=1.9 \mathrm{~s}$ ) correction was applied to the data from the station and plate back face thermocouples to offset the slow response. The compensated temperatures were used to obtain the heat fluxes by assuming the sheet metal is a slug calorimeter; details of this process are described in [3]. A typical set of underwing or station data is shown in Figure 6.

For the purpose of this study, the time averaged fire temperatures and heat fluxes are the main parameters of interest. To obtain these parameters during a relatively steady period, several different averaging methods were evaluated. For each test, a start time for the averaging was chosen based on an evaluation of the response of the underwing or station fire thermocouples located directly above the appropriate pool. The intent was to average the data over a quasi-steady period as shown in Figure 6 . To select an averaging time, the data were analyzed by using fixed averaging periods ranging from 10 to 40 seconds in duration and as well as a moving average method. From this analysis, an averaging time of 20 seconds was selected for all the data.

The temperature measurements from thermocouples on the instrumentation towers were averaged over the same time period. At each elevation, contour plots were obtained by linearly interpolating between fire thermocouple locations.

In each test there appears to be a "hot spot" on the underwing surface; a typical result is shown in a fire temperature contour plot of the Full pool data in Figure 7. At these hot spots, 
the range of the measured heat fluxes appears to be fairly consistent from test to test; only the location of the peak heating appeared to change. The peak heat fluxes on the underwing surface range from $120-150 \mathrm{~kW} / \mathrm{m}^{2}$. The heat fluxes on the fuselage surface show the same type of pattern with peak heat fluxes in the range of $90-120 \mathrm{~kW} / \mathrm{m}^{2}$.

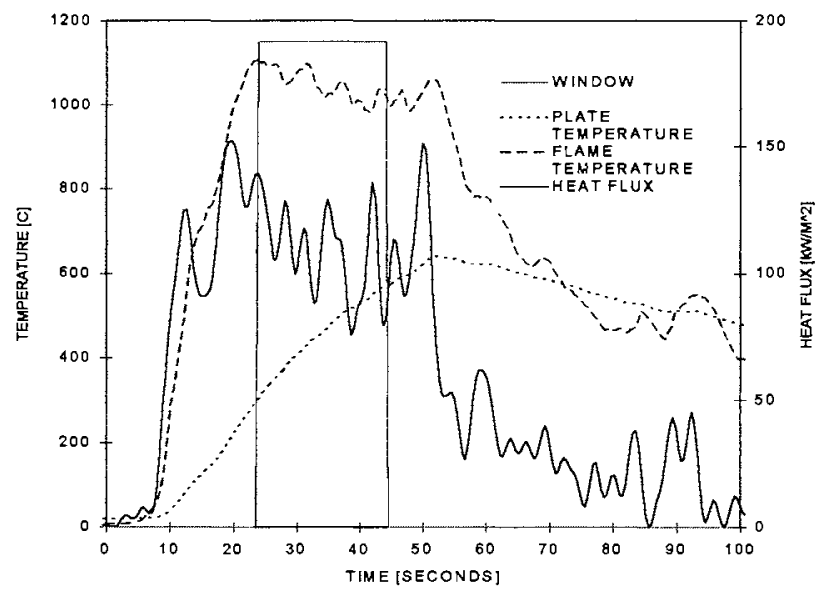

Figure 6 Temperature (Fire and Surface) and Heat Flux Histories at a Typical Station

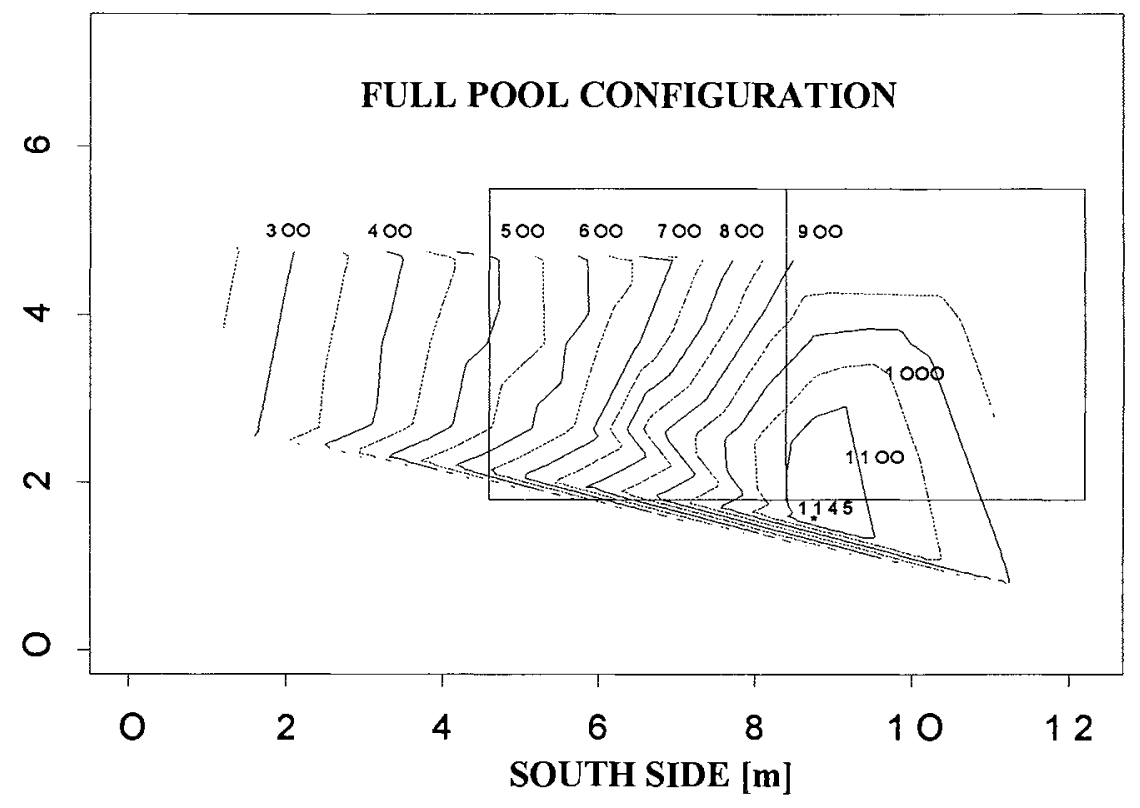

Figure 7 Fire Temperature Contours at the Underwing Surface for a Full Pool Configuration 
From a study of plots of the average surface heat flux as a function of the average fire temperature for the stations and plates for each pool configuration, it was judged that there is minimal variation from test to test and between pool configurations. However, it appears there is a difference between stations and plates. As a result, data from all the tests were combined into two sets, one for stations and one for plates. Polynomial regressions were used to provide mathematical expressions for each data set. Based on a forward F-test procedure [5], second order polynomials provide the best representations of these two data sets.

The regression curve ( $\mathrm{q}_{\mathrm{avg}}$ ), the $95 \%$ confidence interval for the regression curve $\left(\mathrm{CI}_{\text {line }}\right)$, and the standard deviation for the next observation $\left(S_{\text {point }}\right)$ were calculated for each of the data sets. The confidence limits are related to the standard deviations by the expression $\mathrm{S}_{\mathrm{i}}=\mathrm{CI}_{\mathrm{i}} / \mathrm{t}_{\mathrm{n}-2,1-\alpha / 2}$

where $t_{n-2,1-\alpha / 2}$ is the $1-\alpha / 2$ percentage point of the $t$-distribution with $n-2$ degrees of freedom. The standard deviation for the next point is related to the standard deviation of the line by the relation

$\mathrm{S}_{\text {point }}^{2}=\sigma^{2}+\mathrm{S}_{\text {line }}^{2}$

where $\sigma$ is the standard deviation of the residuals. Due to the significantly larger number of data points, the confidence intervals for the current test data are much smaller than those for the earlier tests.

\section{TEMPERATURE - HEAT FLUX MAPPINGS FOR UNDERWING FIRES}

Underwing Surface (Stations)

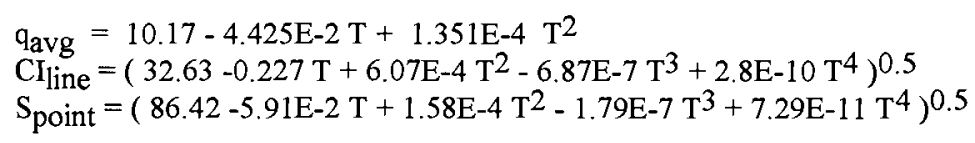

Underwing Fuselage Surface (Plates)

$\mathrm{q}_{\text {avg }}=10.42-1.154 \mathrm{E}-2 \mathrm{~T}+1.068 \mathrm{E}-4 \mathrm{~T}^{2}$
$\mathrm{CI}_{\text {line }}=\left(186.96-1.20 \mathrm{~T}+3.04 \mathrm{E}-3 \mathrm{~T}^{2}-3.37 \mathrm{E}-6 \mathrm{~T}^{3}+1.36 \mathrm{E}-9 \mathrm{~T}^{4}\right)^{0.5}$
$\mathrm{~S}_{\text {point }}=\left(126.6-0.312 \mathrm{~T}+7.91 \mathrm{E}-4 \mathrm{~T}^{3}-8.77 \mathrm{E}-7 \mathrm{~T}^{3}+3.54 \mathrm{E}-10 \mathrm{~T}^{4}\right)^{0.5}$

The temperature is in ${ }^{\circ} \mathrm{C}$. The heat flux is in $\mathrm{kW} / \mathrm{m}^{2}$. The confidence limits are $\mathrm{q} \pm \mathrm{CI}$.

The regression lines are the best fit representation of the mean heat flux, $q_{a v g}$, as a function of temperature. It is unrealistic for the mapping to provide only a mean value of the heat flux because the data illustrates that for a single temperature a range of heat fluxes was measured. To represent both the overall trend and the inherent scatter, the heat flux generated in the mapping is defined as a random number drawn from a normal distribution with a mean of $q_{\text {avg }}$ and a standard deviation of $S_{\text {point }}$.

During an earlier analysis of the existing open pool fire data from large vertical plate and horizontal cylindrical calorimeters $[2,6]$, the F-test procedure indicated that first order models 
provided the best fit to the open pool fire data. However, second order polynomial regression analyses were made of the existing data in order to compare with the current results for which a second order model was indicated.

\section{TEMPERATURE - HEAT FLUX MAPPINGS FOR OPEN POOL FIRES}

\section{Plate Calorimeters - Open Pools}

$$
\begin{aligned}
& \mathrm{q}_{\text {avg }}=103.98-1.335 \mathrm{E}-1 \mathrm{~T}+1.696 \mathrm{E}-4 \mathrm{~T}^{2} \\
& \mathrm{CI}_{\text {line }}=\left(59315-279.1 \mathrm{~T}+0.492 \mathrm{~T}^{2}-3.84 \mathrm{E}-4 \mathrm{~T}^{3}+1.13 \mathrm{E}-7 \mathrm{~T}^{4}\right)^{0.5} \\
& \mathrm{~S}_{\text {point }}=\left(12957-60.66 \mathrm{~T}+0.107 \mathrm{~T}^{2}-8.35 \mathrm{E}-5 \mathrm{~T}^{3}+2046 \mathrm{E}-8 \mathrm{~T}^{4}\right)^{0.5}
\end{aligned}
$$

Horizontal Cylindrical Calorimeters - Open Pools

$$
\begin{aligned}
& \mathrm{q}_{\text {avg }}=-10.56+5.97 \mathrm{E}-2 \mathrm{~T}+6.97 \mathrm{E}-5 \mathrm{~T}^{2} \\
& \mathrm{Cl}_{\text {line }}=\left(21004-113.7 \mathrm{~T}+0.237 \mathrm{~T}^{2}-2.06 \mathrm{E}-4 \mathrm{~T}^{3}+6.87 \mathrm{E}-8 \mathrm{~T}^{4}\right)^{0.5} \\
& \mathrm{~S}_{\text {point }}=\left(4618-24.37 \mathrm{~T}+5.085 \mathrm{E}-2 \mathrm{~T}^{2}-4.42 \mathrm{E}-5 \mathrm{~T}^{3}+1.47 \mathrm{E}-8 \mathrm{~T}^{4}\right)^{0.5}
\end{aligned}
$$

The comparision of the data is shown in Figure 8. Heat fluxes from pool fires under the wing area of an aircraft are lower than the heat fluxes measured with the vertical plate and horizontal cylinder calorimeters in open pool fires. This difference demonstrates the importance of conducting fire tests in as realistic a configuration as possible in order to obtain the proper coupling.

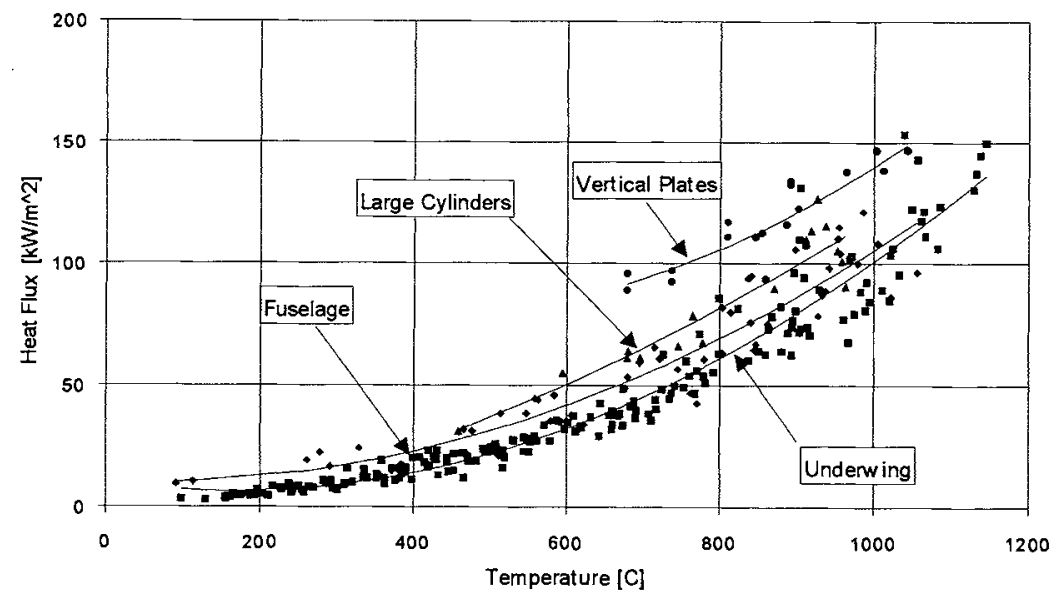

Figure 8 Temperature -Heat Flux Mappings for Four Configurations

To evaluate the possibility of further combining the data, a sequential analysis was performed on the regression curves. A F-test was used to determine if the residuals from a model composed of seperate curves were statistically different from a model with combinations of the curves. The results of the F-test indicate the data are best represented by seperate curves 
for the underwing surface, the fuselage surface, the horizontal cylinders, and the large plate calorimeters. The large differences between the mappings demonstrate the problems that will occur regarding the application of measurements obtained in one fire configuration to a very different configuration.

\section{Extrapolation of Fire Temperatures}

There is significant interest in being able to extrapolate the present results to a wider range of potential fire sizes and fuels to help develop preliminary estimates of fire temperatures in various accident scenarios. Therefore, the fire temperature data from these tests were compared to data for large spill fires at NASA White Sands [7] and to large pool fire data from Sandia [6].

Direct comparisons between the temperatures measured in the current tests at a given elevation and either of the large fire data sets show poor agreement. It appears there is poor agreement because there is no recognition that centerline temperature at a given elevation depends on the size of the fire and the burning rate of the fuel. A three zone model (continuous flame-intermittent flame-plume) was developed by McCaffrey [8] for explaining the relationship between temperature, elevation, and size (through the total heat release rate). It indicates the temperature in the continuous flame zone should be approximately constant.

McCaffrey's model has been used to compare data from large fire tests conducted by Sandia, NASA, and others [6]. By using a scaling factor for the elevation of $Z^{*}=Z / Q^{2 / 5}$ (where $Q$ is the total heat release and $\mathrm{Z}$ is the height), the model appears to successfully scale the data from fires with actual or hydraulic diameters ranging from $3.9 \mathrm{~m}$ to $15 \mathrm{~m}$. However, the temperatures are not constant in the continuous flame zone in these large fires.

A second order polynomial has been fit to this scaled data. The curve is:

$$
\begin{aligned}
& \mathrm{T}_{\text {avg }}=-655.6-1974.8^{*} \mathrm{x}-559.2^{*} \mathrm{x}^{2} \\
& \mathrm{~S}_{\text {point }}=\left(108046+185636 * \mathrm{x}+164958 * \mathrm{x}^{2}+64527 * \mathrm{x}^{3}+9375^{*} \mathrm{x}^{4}\right)^{0.5}
\end{aligned}
$$

where: $x=\log _{10}\left(Z / Q^{2 / 5}\right), Z=$ elevation in meters, and $Q=$ total heat release rate in $k W$.

The centerline fire temperature versus scaled elevation curve is shown in Figure 9 along with the scaled data and the range of average hot spot temperatures measured in the current test series. Points to the left of $x=-1.1$ are considered to be in the continuous flame zone in the fire under still wind conditions. The scatter of the data about the curve diminishes when going from right to left on the curve; this corresponds to moving lower in a fire of a fixed size or staying at a fixed elevation as the fire size increases. When the heat release rate scaling of the elevation is used, there appears to be good agreement between the average hot spot fire temperature data from the current tests and results from the previous tests. The agreement is especially good for the full pool tests. 


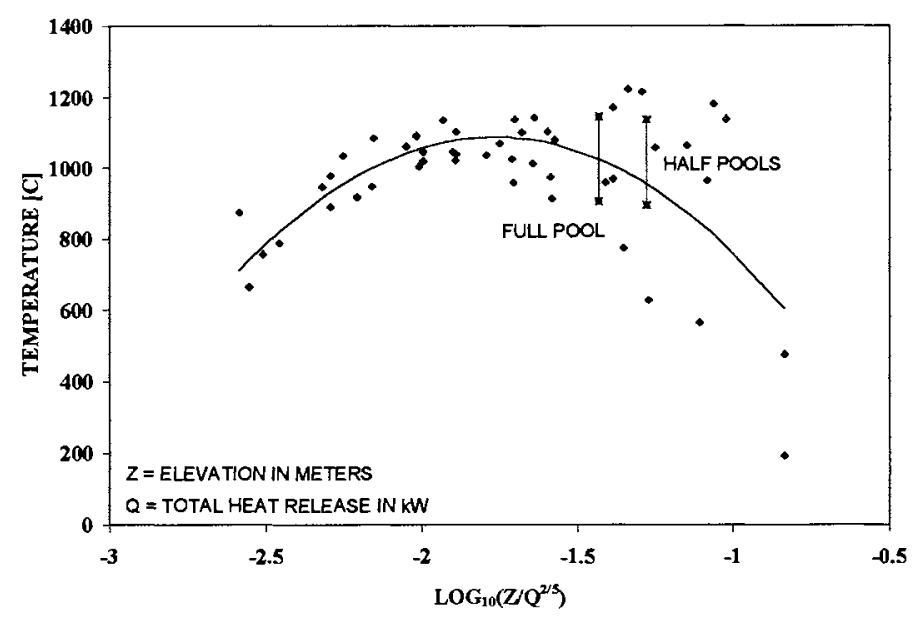

Figure 9 Centerline Temperature versus Scaled Elevation

These scaling results suggest that Equations 7 and 8 could be used to estimate an average centerline temperature at a given elevation once the fire size is determined from an accident scenario analysis. The scatter in the temperature would be a random number drawn from a normal distribution with a mean of zero and a standard deviation of $S_{\text {point. }}$. By using the temperature-to-heat flux mappings developed above, these estimated temperatures could be used to generate an estimate of the heat flux for any of the four specific configurations (Equations 3-6). This approach provides a fast method of generating preliminary estimates of the paired temperature - heat flux distributions for different accident scenarios.

\section{SUMMARY}

A series of tests has been completed to simulate fires that could occur from fuel spills under the wing of transport aircraft. The tests used an existing test fixture which simulates an aircraft wing and an aircraft dock floor. A total of ten test fires were conducted using JP-4 fuel in two pool sizes $(3.7 \mathrm{~m} \times 3.8 \mathrm{~m}$ and $3.7 \mathrm{~m} \times 7.6 \mathrm{~m})$ and three configurations.

Fire temperatures were measured at several elevations with two types of thermocouples. The average temperatures measured with the bare thermocouples tended to be slightly lower than the temperatures measured with the sheathed thermocouples. This indicates that thermocouple design differences are not an important consideration in determining or comparing the average temperatures measured in fire tests. They may be important when determining the variance of the temperatures.

Fire temperature and heat flux data have been obtained for the underwing surface and the underwing fuselage surfaces. Statistical analyses of the data show that separate models are required for correlating fire temperatues and heat fluxes for the underwing and the fuselage surfaces. The heat fluxes from the current test series are significantly lower than the vertical plate calorimeter data and below the cylindrical calorimeter data from open pool fires. The 
current data demonstrate the importance of conducting fire tests in realistic accident configurations and the problems that can occur if heat flux data from one configuration is used to estimate heat fluxes for a very different configuration.

Direct comparisons between the temperatures measured at given elevations in different sizes of fires show poor agreement. However, when a method based on the total heat release rate is used to scale the results between different sized fires, preliminary comparisons of the temperatures show promise. These scaled temperatures may be useful in extending the four temperature - heat flux mappings developed in this report to other scenarios in probablistic risk assessments. The uncertainity associated with this approach will increase as the accident configuration varies from the configurations used in this paper.

\section{ACKNOWLEDGMENT}

This work was supported by the United States Department of Energy under Contract DE-AC04-94AL85000.

\section{REFERENCES}

1. V. F. Nicolette and D. W. Larson, "The Influence of Large, Cold Objects on Engulfing Fire Environments", Heat and Mass Transfer in Fires, J. G. Quintiere and L. Y. Cooper (eds.), ASME HTD Vol. 141, pp. 63-70, 1990.

2. J. J. Gregory, N. R. Keltner, and R. Mata Jr., "Thermal Measurements in Large Pool Fires," Journal of Heat Transfer, Vol. 111, pp. 446-454, May, 1989.

3. E. W. Heinonen, T. D. McCarson Jr., T. J. Stepetic, L. A. Kent, W. Gill, and N. R. Keltner, "Inverted Deluge System (IDS) Development Tests, Volume I: Fire Suppression Tests", CEL-TR-92-71, New Mexico Engineering Research Institute, Albuquerque, NM, June, 1992.

4. L. W. Bickle and N. R. Keltner, "Estimation of Transient Measurement Errors," SAND78-0497, Sandia National Laboratories, Albuquerque, NM, August, 1978.

5. N. R. Draper and H. Smith, "Applied Regression Analysis, Second Edition," John Wiley and Sons, New York, 1981.

6. M. E. Schneider and L. A. Kent, "Measurements of Gas Velocities and Temperatures in a Large Open Pool Fire," Fire Technology, Vol. 25, No. 1, February, 1989.

7. H. T. Johnson, L. J. Linley, and J. A. Mansfield, " Measurement of the Spatial Dependence of Temperature, and Gas and Soot Concentrations Within Large Open Hydrocarbon Fuel Fires, NASA-TM-58230, March, 1982.

8. B. J. McCaffrey, "Purely Buoyant Diffusion Flames: Some Experimental Results", NBSIR 79-1910, National Bureau of Standards ( now NIST ), 1979. 